\title{
The Influence of Angioarchitectural Features on the Success of Endovascular Embolization of Cranial Dural Arteriovenous Fistulas with Onyx
}

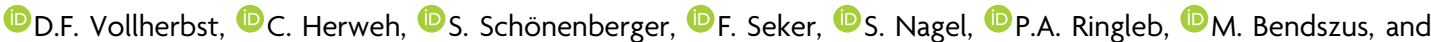 \\ (1) M.A. Möhlenbruch
}

\begin{abstract}
BACKGROUND AND PURPOSE: Endovascular embolization can be an effective treatment for cranial dural arteriovenous fistulas. However, a considerable number of dural arteriovenous fistulas still cannot be treated sufficiently. The purpose of this study was to report our single-center experience of endovascular embolization of dural arteriovenous fistulas with Onyx, including the investigation of the influence of angioarchitectural features on the treatment success.
\end{abstract}

MATERIALS AND METHODS: Clinical data, angioarchitectural features, complications, treatment success (defined as complete symptom remission for low-grade dural arteriovenous fistulas and complete occlusion for high-grade dural arteriovenous fistulas), and occlusion rates were assessed. The influence of various angioarchitectural features (including location, pattern of venous drainage, and quantity and origin of feeding arteries) was investigated using multivariable backward logistic regression.

RESULTS: One hundred four patients with 110 dural arteriovenous fistulas were treated in 132 treatment procedures. Treatment success and complete occlusion rates were $81.8 \%$ and $90.9 \%$, respectively. After a mean follow-up of 23.6 months, $95.5 \%$ of the patients showed complete symptom remission or symptom relief. The overall complication rate was $8.3 \%$ (4.5\% asymptomatic, $2.3 \%$ transient, and $1.5 \%$ permanent complications). Logistic regression showed that $\geq 10$ feeding arteries $(P=.041)$ and involvement of the ascending pharyngeal artery $(P=.039)$ significantly lowered the probability of treatment success. Treatment success tended to be lower for low-grade dural arteriovenous fistulas, Cognard type I dural arteriovenous fistulas, and dural arteriovenous fistulas with involvement of dural branches of the internal carotid artery, however without reaching statistical significance in the multivariable model.

CONCLUSIONS: The presence of multiple feeding arteries and involvement of the pharyngeal artery negatively influence the treatment success of endovascular embolization of cranial dural arteriovenous fistulas with Onyx.

ABBREVIATION: DAVF = dural arteriovenous fistula

C ranial dural arteriovenous fistulas (DAVFs) are pathologic arteriovenous connections between the dural arteries and dural sinuses or cortical veins. According to the risk of hemorrhage, DAVFs can be divided into low-grade DAVFs without an increased risk of hemorrhage and high-grade DAVFs, which are accompanied by an annual risk of hemorrhage of up to $20 \% .{ }^{1}$ The most important risk factors for hemorrhage are cortical venous reflux and ectasia of these cortical veins. ${ }^{2,3}$ Therapy is indicated for low-grade DAVFs in cases of intolerable symptoms, mostly pulsatile tinnitus. For high-grade

Received July 24, 2019; accepted after revision September 26.

From the Departments of Neuroradiology (D.F.V., C.H., F.S., M.B., M.A.M.) and Neurology (S.S., S.N., P.A.R.), Heidelberg University Hospital, Heidelberg, Germany. Please address correspondence to Markus A. Möhlenbruch, MD, Department of Neuroradiology, Heidelberg University Hospital, INF 400, 69120 Heidelberg, Germany; e-mail: markus.moehlenbruch@med.uni-heidelberg.de

http://dx.doi.org/10.3174/ajnr.A6326
DAVFs, therapy is always indicated because of the increased risk of hemorrhage.

Endovascular treatment has become the first-line treatment for most DAVFs. ${ }^{4,5}$ One of the most frequently used techniques is endovascular embolization using liquid embolic agents; Onyx (Medtronic Neurovascular, Irvine, California), a liquid, precipitating, and nonadhesive material, is one of the most commonly used agents. Even though, currently, most patients can be treated successfully by endovascular embolization, a considerable number of DAVFs cannot be treated sufficiently in terms of complete symptom remission for low-grade DAVFs or complete occlusion for high-grade DAVFs. ${ }^{1,6-8}$

The aim of this study was to report our consecutive singlecenter experiences in patients with DAVFs who were treated with endovascular liquid embolization using Onyx, including the assessment of the rates of occlusion, treatment success, and 
complications, and to investigate the influence of angioarchitectural features on the treatment success.

\section{MATERIALS AND METHODS Clinical and Angiographic Analysis}

Approval and informed consent for data collection for this case series were provided by the local ethics committee and by the patients, respectively (registry number: S-247/2009). A retrospective analysis of a prospectively maintained patient data base was performed to identify all subsequent patients with a diagnosis of intracranial DAVFs who were treated at our institution with endovascular embolization using Onyx from October 2008 to June 2019.

Patient demographics, clinical presentation, and clinical follow-up were assessed and recorded. The preinterventional mRS score on the day of the intervention and the postinterventional mRS score at discharge and after 6 months were assessed by a board-certified neurologist. The following angioarchitectural features of the treated DAVFs were extracted by 2 experienced neuroradiologists (D.F.V. and M.A.M. with 6 and 13 years of experience, respectively): location, type (according to the Cognard and Borden classifications ${ }^{2,3}$ ), pattern of venous drainage, number and origin of feeding arteries, and the presence of bilateral feeders and pial artery supply. The documented procedural parameters included the selected feeder for embolization, the number of embolization positions, and the embolization technique. Intra- and postprocedural complications were assessed and graded as asymptomatic, transient, or permanent complications. The initial complete angiographic occlusion was assessed after the last treatment procedure. Overall complete angiographic occlusion was defined as complete occlusion at the last followup examination, diagnosed with DSA, which was performed 6 months after the last treatment, and/or MR imaging, which was performed before discharge and during the follow-up period. Treatment success was defined differently for low-grade DAVFs (no cortical venous reflux/Cognard I-IIa) and high-grade DAVFs (presence of cortical venous reflux/Cognard IIa $+\mathrm{b}$ to IV). For low-grade DAVFs, treatment success was defined as complete symptom remission; for high-grade DAVFs, treatment success was defined as complete occlusion.

\section{Interventional Procedure}

All interventions were performed with the patient under general anesthesia on a biplane angiography suite (Artis Q or Artis zee; Siemens, Erlangen, Germany). Preinterventional bilateral diagnostic angiographies of the internal and external carotid arteries and of the vertebral arteries were performed. Afterward, endovascular embolization was performed with a dimethyl-sulfoxidecompatible microcatheter (Marathon or Apollo, Medtronic Neurovascular; or Sonic, Balt, Montmorency, France) using Onyx 18, 20, or 34 under the roadmap technique. In selected cases, mostly in patients with DAVFs of the transverse and sigmoid sinus, transarterial liquid embolization in combination with transvenous balloon-assisted protection of the venous sinus was performed using a compliant, dimethyl-sulfoxide-compatible venous remodeling balloon (Copernic RC, $8 \times 80$ or $10 \times 80 \mathrm{~mm}$; Balt) as previously described by Vollherbst et al. ${ }^{9}$ In cases in which the microcatheter could not be navigated close enough to the fistula point or in DAVFs with large fistula networks, a duallumen balloon catheter (Scepter XC; MicroVention, Aliso Viejo, California) was used to prevent reflux and to enhance penetration of Onyx into the DAVF. After we terminated the embolization procedure, diagnostic angiographies were performed via the feeder territories for treatment control.

\section{Influence of Angioarchitectural Features on the Treatment Success}

We assessed the influence of the following angioarchitectural factors on the treatment success: location, DAVF type according to the Cognard and Borden classifications, ${ }^{2,3}$ type of venous drainage (into the dural venous sinuses or directly into the cortical veins), the presence of cortical venous reflux (low-grade versus high-grade DAVFs), the number of feeding arteries (DAVFs with $<10$ feeding arteries versus DAVFs with $\geq 10$ feeding arteries, defined as arteries with a length of $\geq 10 \mathrm{~mm}$, measured from the fistula point), the presence of bilateral feeders, the presence of pial artery supply, and involvement of the following feeder territories: middle meningeal artery, occipital artery, internal carotid artery (dural branches), vertebral artery (dural branches), superficial temporal artery, and ascending pharyngeal artery.

\section{Statistics}

SPSS Statistics, Version 25.0 (IBM, Armonk, New York) was used for data analysis. Quantitative data are presented as number (relative frequency) or mean $\pm \mathrm{SD}$. To investigate the influence of angioarchitectural features on the treatment success, we analyzed all selected variables using univariate logistic regression models, with "treatment success" as the outcome variable. Afterward, only the significant variables $(P<.05)$ of this analysis were used in an interim multivariable logistic regression model. This model was adjusted with a variable selection based on the $P$ value with a backward stepwise approach based on the Wald test, resulting in the final multivariable logistic regression model. $P$ values of .05 were defined as the threshold for statistical significance and were not adjusted for multiple testing because this was a hypothesis-generating study. Hence, the $P$ values should be interpreted descriptively. For odds ratios, 95\% confidence intervals were calculated.

\section{RESULTS}

\section{Patient Characteristics}

A total of 190 patients diagnosed with intracranial DAVFs were treated with endovascular therapies between October 2008 and June 2019. Of this population, 104 patients with 110 DAVFs who were treated with endovascular embolization using Onyx in 132 treatment procedures were included in this study. Eighty-six patients were not included for the following reasons: treatment with coiling only ( $n=48$, mainly carotid cavernous fistulas), embolization with other liquid embolic agents $(n=24)$, particle embolization $(n=7)$, and outstanding treatments $(n=7)$. Of the study population, 89 (80.9\%), 17 (15.5\%), and $3(2.7 \%)$ patients were treated in 1,2 , and 3 treatment procedures, respectively. The mean age was $57.4 \pm 13.0$ years, and the male/female ratio was 2:5. Most patients (93.3\%) were symptomatic: Thirty-eight 
(36.5\%) had headache, 34 (32.7\%) had tinnitus, and 13 (12.5\%) had ocular symptoms. Twenty-eight patients $(26.9 \%)$ presented with intracerebral hemorrhage, and 21 patients (20.2\%), with cerebral venous congestion.

\section{Angioarchitectural Features of the Treated DAVFs}

Angioarchitectural features of the treated DAVFs are summarized in Table 1. Most of the DAVFs were located at the transverse

Table 1: Angioarchitectural features

\begin{tabular}{lc}
\hline \multicolumn{1}{c}{ Feature } & No. (relative frequency) \\
\hline Location & $46(41.8 \%)$ \\
Transverse and/or sigmoid sinus & $25(22.7 \%)$ \\
Tentorial/petrosal & $20(18.2 \%)$ \\
Superior sagittal sinus & $7(6.4 \%)$ \\
Torcular & $6(5.5 \%)$ \\
Anterior cranial fossa & $4(3.6 \%)$ \\
Sphenoparietal sinus & $2(1.8 \%)$ \\
Others & \\
Cognard and Borden type & $12(10.9 \%)$ \\
Cognard I & $7(6.4 \%)$ \\
Cognard Ila & $2(1.8 \%)$ \\
Cognard IIb & $10(9.1 \%)$ \\
Cognard Ila+b & $28(25.5 \%)$ \\
Cognard III & $51(46.4 \%)$ \\
Cognard IV & $19(17.3 \%)$ \\
Borden I & $11(10.9 \%)$ \\
Borden II & $79(71.8 \%)$ \\
Borden III & \\
Feeder territories & $96(87.3 \%)$ \\
Middle meningeal artery & $83(75.5 \%)$ \\
Occipital artery & $41(37.3 \%)$ \\
Internal carotid artery (dural & \\
branches) & $41(37.3 \%)$ \\
Verterbral artery (dural branches) & $32(29.1 \%)$ \\
Superficial temporal artery & $27(24.5 \%)$ \\
Ascending pharyngeal artery & \\
Other features & $56(50.9 \%)$ \\
DAVFs with <10 arterial feeders & $54(49.1 \%)$ \\
DAVFs with $\geq 10$ arterial feeders & $56(50.9 \%)$ \\
Bilateral feeders & $41(37.3 \%)$ \\
Pial artery supply &
\end{tabular}

and/or sigmoid sinus (41.8\%), followed by a tentorial/petrosal location (22.7\%), and the superior sagittal sinus (18.2\%). Most DAVFs were high-grade fistulas (Cognard III-IV/Borden III, $71.9 \%)$. The ascending pharyngeal artery was involved in 27 (24.5\%) DAVFs. DAVFs with ascending pharyngeal artery supply were located at the transverse and/or sigmoid sinus (59.3\% of the DAVFs with involvement of the ascending pharyngeal artery), at the tentorium (33.3\%), and at the marginal sinus (7.4\%). The number of arterial feeders was $<10$ in $50.9 \%$ and $\geq 10$ in $49.1 \%$ of the cases. Bilateral feeders were present in $50.9 \%$, and pial artery supply, in $37.3 \%$ of DAVFs. The predominant feeder territories were the middle meningeal artery $(87.3 \%)$ and the occipital artery $(75.5 \%)$.

\section{Treatment Characteristics}

Two sample cases are presented in Figs 1 and 2. Procedural parameters, complications, follow-up and outcome are summarized in Table 2. Most DAVFs were embolized via the middle meningeal artery $(65.2 \%)$ or the occipital artery (23.5\%). The most frequent embolization technique was conventional transarterial embolization (57.6\%), followed by transarterial embolization combined with venous balloon protection (21.2\%) and transarterial embolization with a dual-lumen balloon catheter (14.4\%).

\section{Complications}

The overall complication rate was $8.3 \%$, of which 6 (4.5\%) were asymptomatic, $3(2.3 \%)$ were transient, and 2 (1.5\%) were permanent. The asymptomatic and transient complications included small intracranial hemorrhages, most likely caused by vessel perforation, material-related complications such as catheter occlusion, rupture, or retention, as well as small venous infarctions. Both of the permanent complications were fatal large intracerebral hemorrhages of Cognard type IV/Borden type III DAVFs. The first patient initially presented with severe sinus thrombosis, venous congestion, and obstructive hydrocephalus. In this patient, only subtotal embolization of the DAVF could be
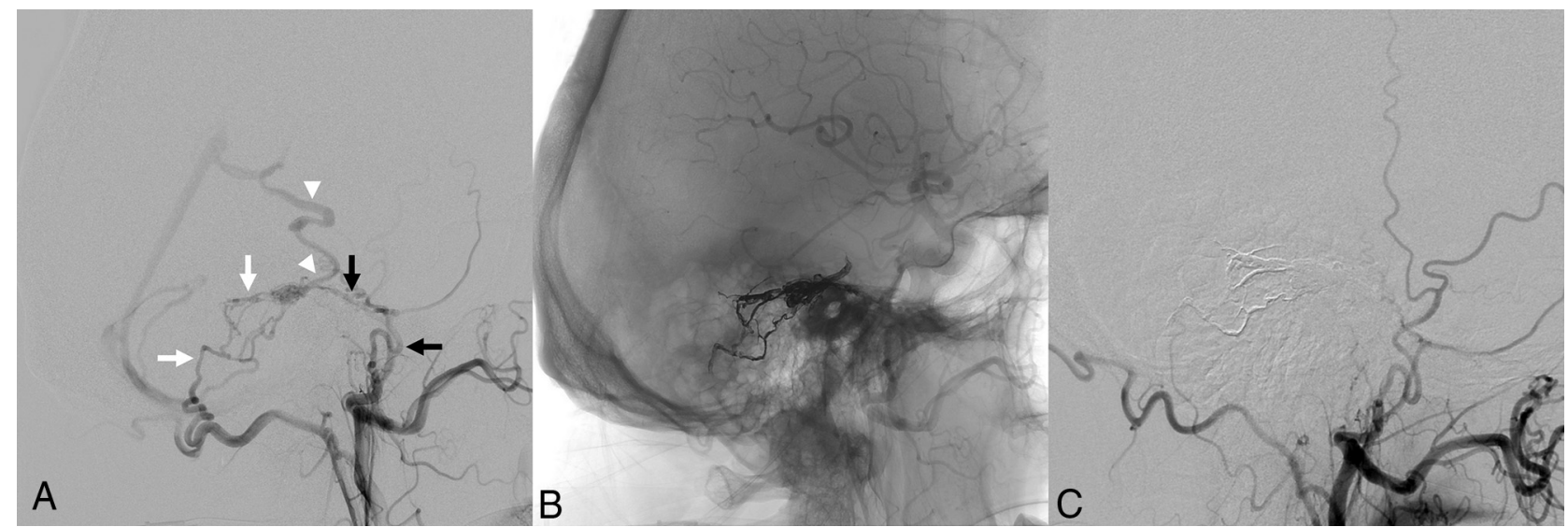

FIG 1. Sample case of a DAVF without angioarchitectural features with a negative influence on the treatment success. A DAVF with direct cortical venous drainage (Cognard type III), located at the tentorium in a 65-year-old man with headaches (A). Involved feeding arteries are the middle meningeal artery (black arrows in A) and the occipital artery (white arrows in A), which shunt directly into a cortical vein (white arrowheads). There were $<10$ feeding arteries, and the ascending pharyngeal artery was not involved. The DAVF could be occluded completely by transarterial embolization with Onyx (B). DSA 6 months after embolization shows stable occlusion of the DAVF (C). 


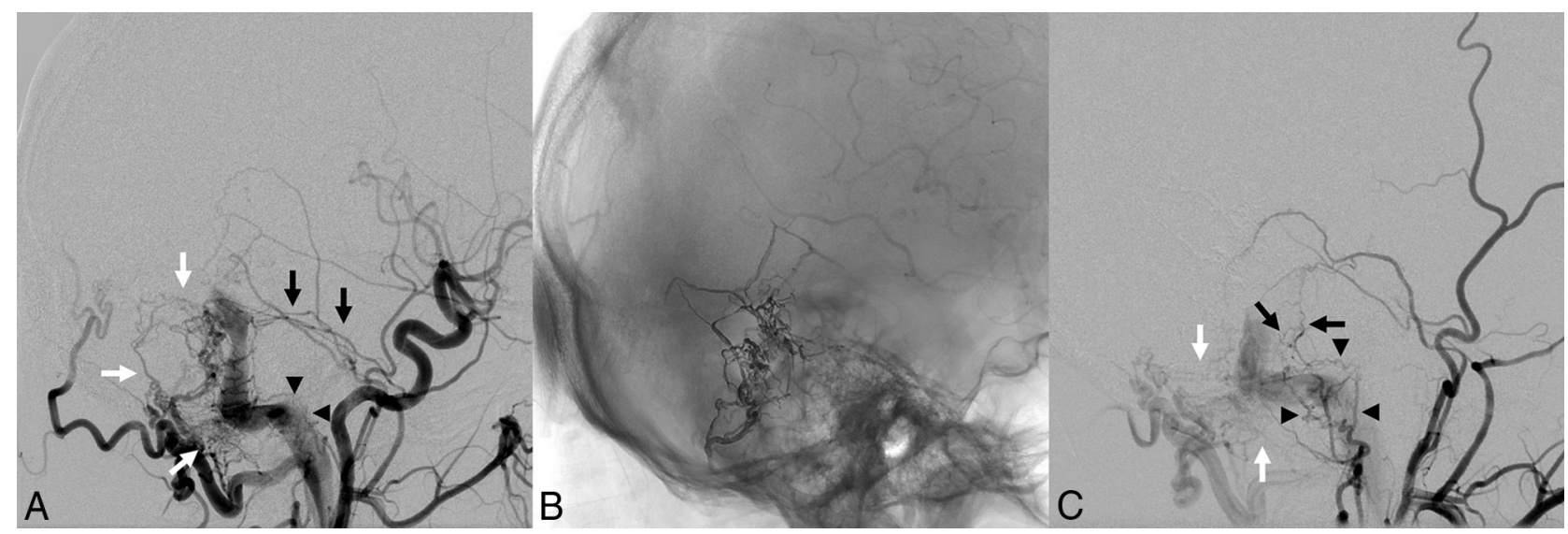

FIG 2. Sample case of a DAVF presenting with angioarchitectural features with a negative influence on the treatment success. A DAVF is located at the transverse and sigmoid sinus with antegrade flow in the sinus (Cognard type I) in a 46-year-old man who presented with severe pulsatile tinnitus (A). Multiple feeders supply the DAVF, including the middle meningeal artery (black arrows in A), the occipital artery (white arrows in A), and the ascending pharyngeal artery (black arrowheads in A). The DAVF was treated by transarterial Onyx embolization in combination with transvenous balloon-assisted protection of the venous sinus $(B)$. The DAVF could not be occluded completely, due to small branches of the middle meningeal artery (black arrows in C) and of the occipital artery (white arrows in C), and particularly because of multiple persistent feeders from the ascending pharyngeal artery (black arrowheads in C), which could not be catheterized distal enough because of their small size and their tortuosity. The patient's symptoms were declining but still persistent at the latest follow-up.

achieved due to the small caliber and the tortuosity of the feeding arteries. Immediately after extubation, the patient developed a large intracerebral hemorrhage, most likely caused by venous congestion. In the second patient, complete angiographic occlusion was achieved in 2 treatment procedures. This patient was asymptomatic after extubation until he experienced increasing headache 3 hours after the second treatment procedure. The subsequent CT scan showed a large intracerebral hemorrhage causing the patient's death on the day of the second treatment procedure. For this patient, no specific cause of the intracerebral hemorrhage could be found.

\section{Occlusion, Success, and Recurrence Rates}

The initial complete angiographic occlusion rate was $78.2 \%$. There was spontaneous occlusion after subtotal initial occlusion in 14 patients $(12.7 \%)$ after a mean time of 6.6 months, resulting in a complete angiographic occlusion rate of $90.9 \%$. After a mean follow-up of 23.6 months, $66.4 \%$ of patients were free of symptoms, $29.1 \%$ showed symptom relief, $2.7 \%$ showed stable symptoms, and $1.8 \%$ showed worsening of symptoms after treatment. Treatment success was achieved in 90 patients (81.8\%). Recurrence after complete angiographic occlusion (diagnosed with DSA) was observed in 4 cases (3.6\%): Three DAVFs were successfully re-treated with endovascular Onyx embolization and 1 DAVF was successfully treated by neurosurgical ligation of the fistula.

\section{Influence of Angioarchitectural Features on the Treatment Success}

The analysis of the influence of angioarchitectural features on the treatment success is summarized in Table 3. The results of the final multivariable logistic regression model are presented in Table 4. Two of the investigated parameters showed a significant negative influence on the treatment success in the multivariable model: $\geq 10$ feeding arteries $(P=.041$; OR, 0.278; 95\% CI, 0.081-
$0.949)$ and involvement of the ascending pharyngeal artery ( $P=.039$; OR, 0.319; 95\% CI, 0.107-0.945). Treatment success tended to be lower for low-grade DAVFs, Cognard type I DAVFs, and DAVFs with involvement of dural branches of the internal carotid artery $(P<.05$ in the univariate models), however without reaching statistical significance in the multivariable model.

\section{DISCUSSION}

The results of this study demonstrate the effectiveness and safety of endovascular embolization of DAVFs using Onyx. On the basis of a comparatively large number of patients with DAVFs treated with endovascular Onyx embolization, the influence of angioarchitectural features on the treatment success was assessed.

Numerous studies in the literature have investigated the efficacy and safety of endovascular embolization of DAVFs or have compared different treatment techniques; however, the influence of angioarchitectural features on the treatment success has not yet been the focus of research., ${ }^{4,6-8,10-12}$ We assessed various angioarchitectural features and analyzed their influence on the treatment success. Of the investigated features, a large number of feeding arteries and involvement of the ascending pharyngeal artery showed a significant negative influence. Treatment success tended to be lower for low-grade DAVFs, Cognard type I DAVFs, and DAVFs with involvement of dural branches of the internal carotid artery without reaching statistical significance. Also, other angioarchitectural features, such as location and Borden type or pial artery supply, did not show significant influence on the treatment success.

Multiple feeding arteries represent a challenge in the treatment of DAVFs. ${ }^{13-16}$ Complete occlusion of DAVFs with multiple feeding arteries can generally be achieved in 3 ways: 1) transarterial embolization of parts of the fistula point and of the proximal draining veins or the sinus with subsequent reflux of 
Table 2: Procedural parameters, complications, follow-up, and outcome

\begin{tabular}{|c|c|}
\hline Parameter & $\begin{array}{l}\text { No. (relative } \\
\text { frequency) / } \\
\text { Mean } \pm \text { SD }\end{array}$ \\
\hline \multicolumn{2}{|l|}{ Selected feeder for embolization } \\
\hline Middle meningeal artery & $86(65.2 \%)$ \\
\hline Occipital artery & $31(23.5 \%)$ \\
\hline Others & $14(10.6 \%)$ \\
\hline \multicolumn{2}{|l|}{ No. of embolization positions } \\
\hline 1 & $103(78.0 \%)$ \\
\hline 2 & $24(18.2 \%)$ \\
\hline 3 & $4(3.0 \%)$ \\
\hline \multicolumn{2}{|l|}{ Embolization technique } \\
\hline Onyx transarterial & $76(57.6 \%)$ \\
\hline $\begin{array}{l}\text { Onyx transarterial combined with venous } \\
\text { balloon protection }\end{array}$ & $28(21.2 \%)$ \\
\hline $\begin{array}{l}\text { Onyx transarterial with a dual-lumen balloon } \\
\text { catheter }\end{array}$ & 19 (14.4\%) \\
\hline Onyx transvenous combined with coiling & $3(2.3 \%)$ \\
\hline Others & $7(5.3 \%)$ \\
\hline \multicolumn{2}{|l|}{ Complications } \\
\hline Overall complications & $11(8.3 \%)$ \\
\hline Asymptomatic complications & $6(4.5 \%)$ \\
\hline Transient symptomatic complications & $3(2.3 \%)$ \\
\hline Permanent complications ${ }^{\mathrm{a}}$ & $2(1.5 \%)$ \\
\hline \multicolumn{2}{|l|}{ Follow-up } \\
\hline Follow-up period (mo) & $23.6 \pm 23.5$ \\
\hline Total follow-up time (patient yr) & 216.3 \\
\hline \multicolumn{2}{|l|}{ Angiographic outcome } \\
\hline Initial complete angiographic occlusion & $86(78.2 \%)$ \\
\hline $\begin{array}{l}\text { Spontaneous occlusion after subtotal } \\
\text { endovascular occlusion }\end{array}$ & $14(12.7 \%)$ \\
\hline $\begin{array}{l}\text { Time period from last treatment to diagnosis } \\
\text { of spontaneous occlusion (months) }\end{array}$ & $6.6 \pm 8.1$ \\
\hline $\begin{array}{l}\text { Overall complete occlusion at last } \\
\text { examination }\end{array}$ & $100(90.9 \%)$ \\
\hline Recurrence & $4(3.6 \%)$ \\
\hline \multicolumn{2}{|l|}{ Clinical outcome } \\
\hline Preinterventional mRS score & $0.8 \pm 0.9$ \\
\hline Postinterventional mRS score at discharge & $0.7 \pm 1.1$ \\
\hline $\begin{array}{l}\text { Postinterventional mRS score at } 6 \text { mo after } \\
\text { treatment }\end{array}$ & $0.4 \pm 0.9$ \\
\hline $\begin{array}{l}\text { Complete symptom remission after } \\
\text { treatment }\end{array}$ & $73(66.4 \%)$ \\
\hline Symptom relief after treatment & $32(29.1 \%)$ \\
\hline Stable symptoms after treatment & $3(2.7 \%)$ \\
\hline Worsening of symptoms after treatment & $2(1.8 \%)$ \\
\hline Treatment success ${ }^{\mathrm{b}}$ & $90(81.8 \%)$ \\
\hline
\end{tabular}

${ }^{a}$ Both permanent complications were lethal intracerebral hemorrhages.

b Defined as complete symptom remission for low-grade DAVFs (no cortical venous reflux/Cognard I-Ila) and complete angiographic occlusion for high-grade DAVFs (to presence of cortical venous reflux/Cognard Ila $+b$ to IV).

embolic agent into the fistula point and the other multiple arterial feeders; 2) transarterial embolization in combination with transvenous balloon protection of the draining veins or the sinus, the latter facilitating retrograde embolization of the whole fistula network; or 3) transvenous coiling of the draining veins or the sinus with or without subsequent transarterial and/or transvenous embolization of the complete DAVF. These embolization techniques are often complex and are not always successful. In this context, it is obvious that the higher the number of feeding arteries, the higher is the chance of incomplete embolization of the DAVF.
In DAVF embolization, particular importance is attributed to the ascending pharyngeal artery, which is regularly involved in the arterial supply of DAVFs (25\% in our study). Embolization of this artery is often avoided because of its potential anastomoses to the internal carotid artery and vertebral arteries as well as its supply to the vasa nervorum of the lower cranial nerves. ${ }^{17}$ In our study, an ascending pharyngeal artery supply was most frequently observed in DAVFs located at the transverse and/or sigmoid sinus and in tentorial DAVFs. Even though treatment success was not significantly different for DAVF locations, the ascending pharyngeal artery supply often contributed to the angioarchitectural complexity of difficult-to-treat DAVFs of these 2 locations. Especially for tentorial DAVFs, which are rare and have a high risk of hemorrhage, involvement of the ascending pharyngeal artery increases the complexity of the angioarchitecture, which can make the endovascular treatment of these difficult-to-treat lesions even more difficult. ${ }^{18}$ These factors are possible explanations for the lower treatment success rate for DAVFs with involvement of this artery in our study.

A possible explanation for the tendency toward a lower treatment success rate for DAVFs without cortical venous reflux (lowgrade DAVFs; Borden I/Cognard I-IIa) can be related to their complex angioarchitecture: multiple arteries shunting into the wall of a venous sinus, which is usually functioning and thus mostly essential for the venous drainage of the brain, forming a large fistula plate rather than a circumscribed fistula point. In most cases, for complete occlusion of the fistula, assistive techniques such as balloon protection of the venous sinus are indispensable, while sacrificing the sinus is accompanied by an increased risk of complications. ${ }^{6,9,13,19}$ These complicating factors result in a greater difficulty of complete embolization of the DAVF and thus make symptom remission less probable.

The special significance and the impact of indirect cortical venous drainage and of pial artery supply on the natural course and on the therapeutic regimen were investigated and discussed in recent studies. ${ }^{7,20}$ However, the presence of these factors did not show a significant influence on the treatment success in our study. With regard to pial artery supply, the number of DAVFs with pial artery supply was relatively high in our study (37\%) compared with research results in the literature. The largest and most recent study with a focus on a pial artery supply of DAVFs is the work of Osada and Krings, ${ }^{20}$ who reported a rate of pial artery supply of $11 \%$ in 204 patients.

For high-grade DAVFs (presence of cortical venous reflux), the primary aim of treatment is complete occlusion of the fistula, to eliminate the risk of hemorrhage. However, for low-grade DAVFs (absence of cortical venous reflux), which are not accompanied by an increased risk of hemorrhage, complete symptom remission is the primary goal of treatment. The rate of symptom remission or relief after endovascular embolization of DAVFs is rarely and heterogeneously reported in the literature and is between $20 \%$ and $80 \% .^{4,6-8,10,11}$ To combine complete angiographic occlusion, as the primary goal for high-grade DAVFs, and complete symptom remission, as the primary goal for lowgrade DAVFs, we defined the treatment success differently for low-grade and high-grade DAVFs: Complete symptom remission was defined as treatment success for low-grade DAVFs, whereas 
Table 3: Influence of angioarchitectural features on the treatment success-summary and univariate models

\begin{tabular}{|c|c|c|c|c|c|c|c|}
\hline \multicolumn{7}{|c|}{ Angioarchitectural Feature, Treatment Success Rate } & \multirow{2}{*}{$\begin{array}{c}\begin{array}{c}P \text { Value } \\
\text { (Univariate } \\
\text { Analysis) }\end{array} \\
.084\end{array}$} \\
\hline Location & $\begin{array}{l}\text { Transverse/ } \\
\text { Sigmoid } \\
\text { Sinus, } \\
80.4 \%\end{array}$ & $\begin{array}{l}\text { Tentorial/ } \\
\text { Petrosal, } \\
72.0 \%\end{array}$ & $\begin{array}{c}\text { Superior } \\
\text { Sagittal } \\
\text { Sinus, } \\
95.0 \%\end{array}$ & $\begin{array}{c}\text { Torcular, } \\
100 \%\end{array}$ & $\begin{array}{c}\text { Anterior } \\
\text { Cranial } \\
\text { Fossa, } \\
83.3 \%\end{array}$ & $\begin{array}{c}\text { Sphenoparietal } \\
\text { Sinus, } 75.0 \%\end{array}$ & \\
\hline Cognard type & I, $60.0 \%$ & Ila, $75.0 \%$ & $\mathrm{Ilb}, 100 \%$ & $\begin{array}{l}\text { Ila }+\mathrm{b} \\
\quad 70.0 \%\end{array}$ & III, $96.4 \%$ & IV, $80.4 \%$ & $.047^{\mathrm{a}}$ \\
\hline Borden type & \multicolumn{2}{|c|}{ I, $66.7 \%$} & & & \multicolumn{2}{|c|}{ III, 86.1\% } & .144 \\
\hline Venous drainage & \multicolumn{4}{|c|}{$\begin{array}{l}\text { Into dural venous } \\
\text { sinus, } 71.4 \%\end{array}$} & \multicolumn{2}{|c|}{$\begin{array}{l}\text { Directly into cortical } \\
\text { veins, } 85.4 \%\end{array}$} & .099 \\
\hline Presence of cortical venous reflux & \multicolumn{4}{|c|}{ Yes, $85.9 \%$} & \multicolumn{2}{|l|}{ No, $61.1 \%$} & .013 \\
\hline No. of feeding arteries & \multicolumn{4}{|c|}{$<10,92.6 \%$} & \multicolumn{2}{|l|}{$\geq 10,71.4 \%$} & $.004^{\mathrm{a}}$ \\
\hline Bilateral feeders & \multicolumn{4}{|c|}{ Yes, $83.3 \%$} & \multicolumn{2}{|l|}{ No, $80.4 \%$} & .686 \\
\hline Pial artery supply & \multicolumn{4}{|c|}{ Yes, 77.8\% } & \multicolumn{2}{|l|}{ No, $83.1 \%$} & .531 \\
\hline $\begin{array}{l}\text { Involvement of the middle } \\
\text { meningeal artery }\end{array}$ & \multicolumn{4}{|c|}{ Yes, $80.2 \%$} & \multicolumn{2}{|l|}{ No, $92.9 \%$} & .252 \\
\hline $\begin{array}{l}\text { Involvement of the occipital } \\
\text { artery }\end{array}$ & \multicolumn{4}{|c|}{ Yes, $80.7 \%$} & \multicolumn{2}{|l|}{ No, $85.2 \%$} & .602 \\
\hline $\begin{array}{l}\text { Involvement of the internal } \\
\text { carotid artery }{ }^{\mathrm{b}}\end{array}$ & \multicolumn{4}{|c|}{ Yes, $70.7 \%$} & \multicolumn{2}{|l|}{ No, $88.4 \%$} & $.020^{\mathrm{a}}$ \\
\hline $\begin{array}{l}\text { Involvement of the vertebral } \\
\text { artery }^{\mathrm{b}}\end{array}$ & \multicolumn{4}{|c|}{ Yes, $75.6 \%$} & \multicolumn{2}{|l|}{ No, $85.5 \%$} & .193 \\
\hline $\begin{array}{l}\text { Involvement of the superficial } \\
\text { temporal artery }\end{array}$ & \multicolumn{4}{|c|}{ Yes, $81.3 \%$} & \multicolumn{2}{|l|}{ No, $82.1 \%$} & .921 \\
\hline $\begin{array}{l}\text { Involvement of the ascending } \\
\text { pharyngeal artery }\end{array}$ & \multicolumn{4}{|c|}{ Yes, $61.5 \%$} & \multicolumn{2}{|l|}{ No, $88.1 \%$} & $.002^{a}$ \\
\hline
\end{tabular}

Statistically significant.

${ }^{b}$ Dural branches.

Table 4: Influence of angioarchitectural features on the treatment success-final multivariable logistic regression model

\begin{tabular}{lcc}
\multicolumn{1}{c}{ Angioarchitectural Feature } & $P$ Value & Odds Ratio (95\% Confidence Interval) \\
\hline No. of feeding arteries & .041 & $0.278(0.081-0.949)$ \\
Involvement of the ascending pharyngeal artery & .039 & $0.319(0.107-0.945)$ \\
\hline
\end{tabular}

complete angiographic occlusion was defined as treatment success for high-grade DAVFs.

The overall occlusion rate of $90.9 \%$ in this study is in line with results of studies in the current literature. For a relatively large series of 251 patients treated with different endovascular techniques (not only Onyx embolization), Gross et $\mathrm{al}^{4}$ reported an initial angiographic occlusion rate of $70 \%$ and a rate of spontaneous occlusion after partial treatment of $8 \%$, resulting in an overall complete occlusion rate of $78 \%$. For studies reporting DAVF embolization with Onyx as the only embolic agent, the pooled initial angiographic occlusion rate was $82 \%$ in a recent meta-analysis. $^{21}$ The overall complete occlusion rate for embolization with Onyx only ranges between $83.3 \%$ and $100 \%$ in the most recent studies. ${ }^{7,8,11}$

Recent studies in the literature on endovascular Onyx embolization of DAVFs reported overall complication rates between $8 \%$ and $24 \%{ }^{4,6-8,11}$ The complication rate of $8.3 \%$ in our study is thus comparable with that in these studies. In our study, no case of cranial nerve palsy was observed. However, cranial nerve palsy is a rare but regularly observed complication after endovascular embolization of DAVFs. The rate of cranial nerve palsy lies between $0 \%$ and $6 \%{ }^{4,7,8,10,11,21}$ in the latest studies, with a pooled rate of $2 \%$ according to the above-mentioned meta-analysis of
Sadeh-Gonike et al. ${ }^{22}$ Both of the 2 fatal complications in our study were large intracranial hemorrhages. One of these cases occurred after subtotal embolization of a high-grade DAVF, which should be avoided in any case, if possible. For the second patient, no specific reason for the lethal intracerebral hemorrhage could be found.

A potential limitation of this study is the relatively low number of patients. However, to the best of our knowledge, this is the largest known population sample for a study reporting DAVF embolization with Onyx as the only embolic agent. Furthermore, this was a single-center study with retrospective analysis of prospectively maintained data, potentially limiting the study findings. A further limitation with regard to the analysis of the angioarchitectural features is that some of the analyzed angioarchitectural features influence each other (eg, number of feeding arteries and the individual feeder territories).

\section{CONCLUSIONS}

Endovascular embolization of cranial DAVFs with Onyx is safe and offers high rates of occlusion and of symptom remission. The presence of multiple feeding arteries and involvement of 
the pharyngeal artery negatively influence the treatment success of endovascular embolization of cranial DAVFs with Onyx.

Disclosures: Dominik F. Vollherbst-UNRELATED: Travel/Accommodations/ Meeting Expenses Unrelated to Activities Listed: MicroVention and Stryker, Comments: travel support outside this work.* Christian Herweh-UNRELATED: Consultancy: Brainomix, Oxford UK. Simon Nagel—UNRELATED: Board Membership: Brainomix; Grants/Grants Pending: Cerenovus*; Payment for Lectures Including Service on Speakers Bureaus: Pfizer, Boehringer Ingelheim. Peter RinglebUNRELATED: Consultancy: Advisory Board for Boehringer Ingelheim; Grants/Grants Pending: German Research Foundation; Payment for Lectures Including Service on Speakers Bureaus: Bayer AG, Boehringer Bristol-Myers Squibb, Pfizer, Daiichi Sankyo, Comments: lecture fee. Martin Bendszus — UNRELATED: Board Membership: Vascular Dynamics, Boehringer, Guerbet, Roche; Consultancy: B. Braun Medical, Roche, Guerbet; Grants/Grants Pending: German Research Foundation, European Union, Hopp Foundation, Novartis, Siemens, Stryker, Medtronic, Guerbet*; Payment for Lectures Including Service on Speakers Bureaus: Novartis, Teva Pharmaceutical Industries, Guerbet, Merck \& Co, Grifols. Markus A. Möhlenbruch—UNRELATED: Consultancy: MicroVention, Medtronic, Stryker; Grants/Grants Pending: Balt Extrusion, MicroVention*; Payment for Lectures Including Service on Speakers Bureaus: Medtronic, MicroVention, Stryker. ${ }^{\star}$ Money paid to the institution.

\section{REFERENCES}

1. Gross $\mathrm{BA}, \mathrm{Du} \mathrm{R}$. The natural history of cerebral dural arteriovenous fistulae. Neurosurgery 2012;71:594-602; discussion 602-03 CrossRef Medline

2. Borden JA, Wu JK, Shucart WA. A proposed classification for spinal and cranial dural arteriovenous fistulous malformations and implications for treatment. J Neurosurg 1995;82:166-79 CrossRef Medline

3. Cognard C, Gobin YP, Pierot L, et al. Cerebral dural arteriovenous fistulas: clinical and angiographic correlation with a revised classification of venous drainage. Radiology 1995;194:671-80 CrossRef Medline

4. Gross BA, Albuquerque FC, Moon K, et al. Evolution of treatment and a detailed analysis of occlusion, recurrence, and clinical outcomes in an endovascular library of 260 dural arteriovenous fistulas. J Neurosurg 2017;126:1884-93 CrossRef Medline

5. Rammos S, Bortolotti C, Lanzino G. Endovascular management of intracranial dural arteriovenous fistulae. Neurosurg Clin $\mathrm{N} \mathrm{Am}$ 2014;25:539-49 CrossRef Medline

6. Ertl L, Bruckmann H, Kunz M, et al. Endovascular therapy of lowand intermediate-grade intracranial lateral dural arteriovenous fistulas: a detailed analysis of primary success rates, complication rates, and long-term follow-up of different technical approaches. $J$ Neurosurg 2017;126:360-67 CrossRef Medline

7. Mantilla D, Le Corre M, Cagnazzo F, et al. Outcome of transarterial treatment of dural arteriovenous fistulas with direct or indirect cortical venous drainage. J Neurointerv Surg 2018;10:958-63 CrossRef Medline

8. Rangel-Castilla L, Barber SM, Klucznik R, et al. Mid- and long-term outcomes of dural arteriovenous fistula endovascular management with Onyx: experience of a single tertiary center. J Neurointerv Surg 2014;6:607-13 CrossRef Medline

9. Vollherbst DF, Ulfert C, Neuberger U, et al. Endovascular treatment of dural arteriovenous fistulas using transarterial liquid embolization in combination with transvenous balloon-assisted protection of the venous sinus. AJNR Am J Neuroradiol 2018;39:1296-1302 CrossRef Medline

10. Baltsavias G, Valavanis A. Endovascular treatment of 170 consecutive cranial dural arteriovenous fistulae: results and complications. Neurosurg Rev 2014;37:63-71 CrossRef Medline

11. Chandra RV, Leslie-Mazwi TM, Mehta BP, et al. Transarterial Onyx embolization of cranial dural arteriovenous fistulas: long-term follow-up. AJNR Am J Neuroradiol 2014;35:1793-97 CrossRef Medline

12. Piippo A, Niemela M, van Popta J, et al. Characteristics and longterm outcome of $\mathbf{2 5 1}$ patients with dural arteriovenous fistulas in a defined population. J Neurosurg 2013;118:923-34 CrossRef Medline

13. Abud TG, Nguyen A, Saint-Maurice JP, et al. The use of Onyx in different types of intracranial dural arteriovenous fistula. AJNR Am J Neuroradiol 2011;32:2185-91 CrossRef Medline

14. Cognard C, Januel AC, Silva NA Jr, et al. Endovascular treatment of intracranial dural arteriovenous fistulas with cortical venous drainage: new management using Onyx. AJNR Am J Neuroradiol 2008;29:235-41 CrossRef Medline

15. Gandhi D, Chen J, Pearl M, et al. Intracranial dural arteriovenous fistulas: classification, imaging findings, and treatment. AJNR Am J Neuroradiol 2012;33:1007-13 CrossRef Medline

16. Roy D, Raymond J. The role of transvenous embolization in the treatment of intracranial dural arteriovenous fistulas. Neurosurgery 1997;40:1133-41; discussion 1141-44 Medline

17. Gross BA, Albuquerque FC, Moon K, et al. The road less traveled: transarterial embolization of dural arteriovenous fistulas via the ascending pharyngeal artery. J Neurointerv Surg 2017;9:97-101 CrossRef Medline

18. Lawton MT, Sanchez-Mejia RO, Pham D, et al. Tentorial dural arteriovenous fistulae: operative strategies and microsurgical results for six types. Neurosurgery 2008;62:110-24; discussion 124-25 Medline

19. Piechowiak E, Zibold F, Dobrocky T, et al. Endovascular treatment of dural arteriovenous fistulas of the transverse and sigmoid sinuses using transarterial balloon-assisted embolization combined with transvenous balloon protection of the venous sinus. AJNR Am J Neuroradiol 2017;38:1984-89 CrossRef Medline

20. Osada T, Krings T. Intracranial dural arteriovenous fistulas with pial arterial supply. Neurosurgery 2019;84:104-15 CrossRef Medline

21. Sadeh-Gonike U, Magand N, Armoiry X, et al. Transarterial Onyx embolization of intracranial dural fistulas: a prospective cohort, systematic review, and meta-analysis. Neurosurgery 2018;82:854-63 CrossRef Medline

22. Johnson CS, Chiu A, Cheung A, et al. Embolization of cranial dural arteriovenous fistulas in the liquid embolic era: a Sydney experience. J Clin Neurosci 2018;49:62-70 CrossRef Medline 